DOE/MC / 11076--3202

DE93 000.241 


\title{
Evaluation of Coal Pretreatment Prior to Co-Processing
}

\section{Topical Report}

\author{
F.D. Guffey \\ F.A. Barbour \\ R.F. Blake
}

December 1991

Work Performed Under Contract No.: DE-FC21-86MC11076

For

U.S. Department of Energy

Office of Fossil Energy

Morgantown Energy Technology Center

Morgantown, West Virginia

By

University of Wyoming Western Research Institute

Laramie, Wyoming 


\section{DISCLAIMER}

This report was prepared as an account of work sponsored by an agency of the United States Government. Neither the United States Government nor any agency thereof, nor any of their employees makes any warranty, express or implied, or assumes any legal liability or responsibility for the accuracy, completeness or usefulness of any information, apparatus, product, or process disclosed, or represents that its use would not infringe privately owned rights. Reference herein to any specific commercial product, process, or service by trade name, trademark, manufacturer, or otherwise, does not necessarily constitute or imply its endorsement, recommendation, or favoring by the United States Government or any agency thereof. The views and opinions of authors expressed herein do not necessarily state or reflect those of the United States Government or any agency thereof.

This report has been reproduced directly from the best available copy.

Available to DOE and DOE contractors from the Office of Scientific and Technical Information, P.O. Box 62, Oak Ridge, TN 37831; prices available from (615)576-8401, FTS 626-8401.

Available to the public from the National Technical Information Service, U.S. Department of Commerce, 5285 Port Royal Rd., Springfield, VA 22161. 


\title{
Evaluation of Coal Pretreatment Prior to Co-Processing
}

\author{
Topical Report
}

\author{
F.D. Guffey \\ F.A. Barbour \\ R.F. Blake
}

Work Performed Under Contract No.: DE-FC21-86MC11076

\author{
For \\ U.S. Department of Energy \\ Office of Fossil Energy \\ Morgantown Energy Technology Center \\ P.O. Box 880 \\ Morgantown, West Virginia 26507-0880
}

\author{
By \\ University of Wyoming \\ Western Research Institute \\ P.O. Box 3395 \\ University Station \\ Laramie, Wyoming 82071
}

December 1991 
LIST OF TABLES $\ldots \ldots \ldots \ldots \ldots \ldots \ldots \ldots \ldots \ldots \ldots \ldots \ldots \ldots \ldots \ldots \ldots \ldots$

SUMMARY.................................... iv

INTRODUCTION $\ldots \ldots \ldots \ldots \ldots \ldots \ldots \ldots \ldots \ldots \ldots \ldots \ldots \ldots \ldots \ldots \ldots \ldots \ldots \ldots \ldots$

EXPERIMENTAL. ................................ 2

Resource Preparation and Verification................. 2

Experimental Apparatus.......................... 5

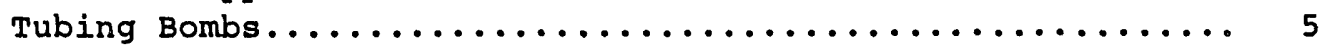

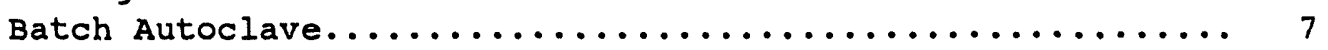

Analytical Procedures............................. 7

RESULTS AND DISCUSSION.......................... 8

Evaluation of Catalyst Dispersion................... 8

Catalyst screening studies...................... 8

Evaluation of Pretreatment and co-Processing........... 10

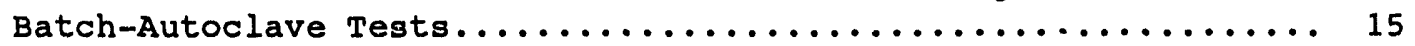

Experiments Investigating Dried Coal................ 15

Experiments Investigating Thermally Pretreated Coal....... 16

Product Analysis............................. 18

CONCLUSIONS.................................... 19

ACKNOWLEDGEMENT . ............................... 20

DISCLAIMER. ................................... 20

REFERENCES................................... 21 
1. Physical and Chemical Properties of the Coal-Derived Mild Gasification Liquid........................ 3

2. Proximate and Ultimate Analyses of Illinois No. 6 Coal and Pittsburgh No. 8 Filter Cake Coal.................... 4

3. Proximate and Ultimate Analyses of Illinois No. 6 Coal Thermally Pretreated in the PDU.....................

4. Results from Experiments screening Catalytic Activity for Co-Processing IFB Dried Coals.......................

5. Results from Tubing Bomb Experiments Evaluating Co-Processing Illinois No. 6 Coal (Dried in the IFB) with Iron Pentacarbonyl as the Catalyst precursor......................... 11

6. Results from Tubing Bomb Experiments Evaluating Co-Processing Filter Cake Product from Pittsburgh No. 8 seam Coal (Dried in the IFB) with Iron Pentacarbonyl as the Catalyst Precursor..... 13

7. Relative Product Distribution for the Experiments Conducted with the Filter cake Product Using Pretreatment at $275^{\circ} \mathrm{C}\left(527^{\circ} \mathrm{F}\right) 14$

8. Results from Stirred Batch Autoclave Experiments Co-Processing IFB Dried Illinois No. 6 Coal with Iron Pentacarbonyl as the Catalyst Precursor at $400^{\circ} \mathrm{C}\left(752^{\circ} \mathrm{F}\right) \ldots \ldots \ldots 15$

9. Results from Stirred Batch Autoclave Experiments Co-Processing Thermally Pretreated Illinois No. 6 Coal with Iron Pentacarbonyl as the Catalyst Precursor.................

10. Results from Analysis of THF-Soluble Product and Cyclohexane Fractions from Batch Autoclave Experiments Investigating Illinois No. 6 Coal............................ 
The Western Research Institute is currently developing a mild gasification process for the recovery of a stabilized char product for use as a fuel. A liquid product of limited value is produced during the mild gasification process that may be suited as a co-processing vehicle for coal-oil co-processing. Research was conducted to evaluate coprocessing of this mild gasification liquid with coal. The two major areas of research discussed in this report are: (1) coal pretreatment with a coal-derived liquid to induce coal swelling and promote catalyst dispersion and (2) co-processing coal that has been thermally pretreated in the presence of the mild gasification liquid.

Dispersion of the catalyst precursor was investigated using two oilsoluble forms of iron. For this research, coal was pretreated in the presence of the mild gasification liquid to induce coal swelling and promote catalyst dispersion. This was followed by co-processing the reactants in tubing bombs under hydrogen pressure. The thermally pretreated coal that was used in the second research area was prepared in another phase of this overall effort. The coal was thermally pretreated in the presence of an inert atmosphere, immersed in preheated heavy oil, and the coal-oil slurry was further processed to yield a dry product for our co-processing studies. The thermally pretreated coal was co-processed in a batch-autoclave with additional liquid under hydrogen pressure to produce a coal liquid that was upgraded as compared to the original mild gasification liquid.

The results of the investigation to evaluate coal pretreatment intended to induce coal swelling and promote catalyst dispersion suggest that iron pentacarbonyl is more effective as a catalyst precursor than is ferrocene for conversion of the Illinois No. 6 coal and the filter cake coal product derived from Pittsburgh No. 8 coal. Induced coal swelling in the presence of the mild gasification produced liquid is a viable means of dispersing the catalyst. However, the two coals studied exhibit different degrees of improved yield from the pretreatment. The filter cake product (bituminous) exhibited a higher degree of swelling and better catalyst dispersion, as defined by increased coal conversion, than did the Illinois No. 6 coal (subbituminous). The filter cake product also showed a broader range of coal conversion percentages because of the induced swelling.

The results of the investigation to evaluate co-processing of coal that has been thermally pretreated in the presence of the mild gasification liquid indicate that the thermal pretreatment adversely affected the coal-oil so-processing under hydrogen pressure. Thermally pretreated coals co-processed under a hydrogen atmosphere and without benefit of catalyst exhibited about 86 wt 8 conversion as compared to 96 wt 8 for coal that was only thermally dried. The addition of the iron pentacarbonyl catalyst precursor to the thermally pretreated coals did improve the conversion to near that of the dried coal. Results from analysis of the product obtained from co-processing the Illinois No. 6 coal showed it was upgraded in terms of oxygen content and hydrogen to carbon atomic ratio when compared to the mild gasification liquid. 


\section{INTRODUCTION}

Western Research Institute (WRI) has been conducting research to develop a mild gasification process to produce a stabilized char product for use as a fuel (Merriam et al. 1990). The process also produces a heavy liquid with limited economic value. The composition of this liquid does not make it attractive as refinery feedstock because of its high molecular weight and heteroatom content. This liquid, because of its limited economic value, may be suited as a co-processing vehicle for coal-oil co-processing.

Coal-oil co-processing began receiving attention in the early 1970's as a potential process for simultaneously upgrading heavy oils and coal to produce liquid products more suited for introduction into refineries. Reported results have demonstrated that the co-processing concept can be applied to a variety of feedstocks and that yields can be increased over processing the two feedstocks independently through synergistic reactions (speight and Moschopedis 1986; McMillen et al. 1991). Applying co-processing technology to upgrading the liquid produced from mild gasification of coal offers several technological benefits.

A recent study has shown phase splitting between aromatic and aliphatic hydrocarbons at elevated temperature and pressure (DukhedinLalla et al. 1990). Phase splitting can result in decreased solubility of coal dissolution products if the co-processing liquid is an aliphatic, petroleum-based residuum. The solubility problem is believed to have a direct effect on liquid yield because, when not in solution, coal dissolution products tend to undergo retrograde reactions that decrease liquid product yield. The mild gasification liquid is highly aromatic and, since it is a coal-derived liquid, it contains functional groups similar to the coal structure. Using this liquid as a coprocessing liquid should improve coal conversion yields because of increased solubility of the coal dissolution products.

Swelling of coal before it undergoes liquefaction reactions has been shown to increase the liquid product yield (Joseph 1991). Coal can be made to swell by two procedures: (1) the interaction with polar solvents, and (2) thermally at moderate temperatures. In addition, it has been shown that a coal swollen in a solvent will allow the solvent to penetrate the coal structure and disperse a catalyst dissolved in it (Warzinski 1990). The mild gasification liquid is polar because of the high heteroatom content and has the potential of inducing coal swelling. If an oil soluble catalyst precursor is used, it can be dissolved in the liquid and be readily dispersed as the coal swells. Uniform dispersion of the catalyst will improve liquid yield during co-processing.

Western Research Institute has been conducting research to evaluate co-processing of a mild gasification liquid with coal. The total research effort to investigate co-processing had three objectives. The first objective was to evaluate the potential of co-processing coal and the mild gasification liquid in the 2-inch process development unit (PDU) available at WRI. This process relies on thermal decomposition of the reactants in the absence of additional hydrogen to produce an upgraded liquid product. The second objective was to evaluate the 
potential of using the coal-derived solid produced from the PDU (first objective) as a feedstock for additional co-processing. This coprocessing concept addresses the second objective and utilizes added hydrogen in the form of high pressure hydrogen gas to recover additional liquid product from the unconverted coal and residual liquid associated with the solid product from the 2-inch PDU. The third objective was to evaluate coal pretreatment to induce coal swelling and promote dispersion of iron-based, disposable catalyst precursors, into the coal structure.

The results from the investigations addressing the first objective have been reported and have demonstrated acceptable yields of distillable liquid product from the process (Vaillancourt et al. 1991). The research discussed in this report provides the results obtained from research addressing the remaining two objectives.

A series of experiments were performed in the WRI batch autoclave to evaluate co-processing the coal-derived solid product generated from the PDU as described by Vaillancourt et al. (1991). Our research considered the co-processing studies performed in the 2-inch PDU (in the absence of added hydrogen) as a moderately severe thermal pretreatment step prior to co-processing the solid product with the mild gasification liquid in the batch autoclave under a high pressure hydrogen atmosphere. As stated above, the objective of our effort was to evaluate the potential of obtaining additional liquid product from the coal-derived solid material. The reader should note that the work performed by Vaillancourt et al. (1991) refers to the solid product as a "coprocessing" product and in our report, the same product is defined as a product from thermal pretreatment. This difference in terminology does not imply a different product, only a difference in the way the material is viewed in terms of the individual project objective.

A second series of experiments were performed in tubing bombs to address induced coal swelling as a pretreatment approach to facilitate the dispersion of the catalyst. Coal that had only been dried was pretreated and co-processed in the tubing bombs to evaluate increased coal conversion as a function of the pretreatment conditions. Increased coal swelling and improved catalyst dispersion from the pretreatment step were monitored by evaluating increased coal conversion and hydrogen consumption.

\section{EXPERIMENTAL}

\section{Resource Preparation and Verification}

The sample of coal-derived liquid used as the co-processing vehicle was generated by mild gasification of coal during another project conducted by Western Research Institute (Merriam et al. 1990). The relevant physical properties of the mild gasification liquid are listed in rable 1. It can be defined as a dense material (specific gravity 1.04) containing a large percentage of water. The dry oil has an elemental composition typical of heavy, coal-derived liquids. The carbon content is low and it contains an appreciable concentration of oxygen. 
Table 1. Physical and Chemical properties of the Coal-Derived Mild Gasification Liquid

\begin{tabular}{lc}
\hline Moisture, wt \& & 12.99 \\
Ash, wt \& & 0.01 \\
Oil, wt \& & 87.00 \\
Carbon, wt \& & 77.3 \\
Hydrogen, wt \& & 8.3 \\
Nitrogen, wt \& & 1.0 \\
Sulfur, wt \& & 0.5 \\
Oxygen, wt \& & 13.2 \\
Specific Gravity & 1.04 \\
\hline
\end{tabular}

The sample of coal-derived liquid was divided into two portions for use in the tubing bomb and batch autoclave experiments. The amount of liquid used for the tubing bomb experiments was the smaller of the two portions and was dewatered by azeotropic distillation with benzene. The sample of the liquid used for the batch autoclave studies was dried by heat soaking the material at $85^{\circ} \mathrm{C}\left(185^{\circ} \mathrm{F}\right)$ and decanting any free water. Heat soaking lowered the water content from 13 wt 8 to approximately 2 wt $z$ as determined by azeotropic distillation of a sm'sl quantity of the liquid.

Two coals were selected for this study. The Herrin seam coal (Illinois No. 6) is a subbituminous coal obtained from the Peabody Coal Company, River King Mine, pit 3, near New Athens, Illinois. The coalderived material referred to as the filter cake coal is the cleaned product from Pittsburgh No. 8 seam coal (bituminous) and was supplied by Consolidation coal Company, Library, Pennsylvania. The results of the ultimate and proximate analyses of the coals are listed in Table 2. Both of the coal samples were dried in an inclined fluidized bed (IFB) dryer as part of a larger study evaluating coal pretreatment (Vaillancourt et al.. 1991). The coal samples were collected directly fiom the dryer and covered with a nitrogen atmosphere. The samples were stored at room temperature under a nitrogen atmosphere until used.

The thermally pretreated coals selected for this study were produced from the Illinois No. 6 coal as the solid product from the PDU (Vaillancourt et al. 1991). The results of proximate and ultimate analyses of the thermally pretreated coals are listed in Table 3 . Three different thermal pretreatment regimes were evaluated to determine what, if any, effects the thermal pretreatment had on coal conversion during coal-oil co-processing. The numbers designating the different pretreatment regimes are those assigned during the tests discussed in a previous report (Vaillancourt et al. 1991). 
Table 2. Proximate and Ultimate Analyses of Illinois No. 6 Coal and Pittsburgh No. 8 Filter Cake Coal

\begin{tabular}{|c|c|c|c|c|c|}
\hline & & Proxi & Anal & & \\
\hline Coal & & Moisture & Ash & Volatile & Fixed Carbon \\
\hline Illinois No. 6 & $\begin{array}{l}\mathrm{AR}^{\mathrm{a}} \\
\mathrm{MF}^{\mathrm{b}} \\
\mathrm{MAF}^{\mathrm{c}}\end{array}$ & 3.4 & $\begin{array}{l}10.5 \\
10.9\end{array}$ & $\begin{array}{l}36.6 \\
37.9 \\
42.5\end{array}$ & $\begin{array}{l}49.5 \\
51.2 \\
57.5\end{array}$ \\
\hline Filter Cake & $\begin{array}{l}\text { AR } \\
\text { MF } \\
\text { MAF }\end{array}$ & 1.3 & $\begin{array}{l}9.8 \\
9.9\end{array}$ & $\begin{array}{l}33.0 \\
33.4 \\
37.1\end{array}$ & $\begin{array}{l}56.0 \\
56.7 \\
63.0\end{array}$ \\
\hline
\end{tabular}

\section{Ultimate Analysis}

\begin{tabular}{lllcccc}
\hline Coal & & Carbon & Hydrogen & Nitrogen & Sulfur & Oxygen \\
\hline \multirow{2}{*}{ Illinois No. 6} & AR & 64.0 & 4.9 & 1.2 & 3.5 & 15.8 \\
& MF & 66.3 & 4.7 & 1.2 & 3.6 & 13.3 \\
& MAF & 74.4 & 5.3 & 1.3 & 4.0 & 15.0 \\
\hline \multirow{2}{*}{ Filter Cake } & AR & 73.7 & 5.0 & 1.4 & 1.4 & 8.7 \\
& MF & 74.7 & 4.9 & 1.4 & 1.4 & 7.7 \\
& MAF & 82.9 & 5.4 & 1.6 & 1.6 & 8.5 \\
\hline
\end{tabular}

\footnotetext{
a AR - As Received

b MF - Moisture Free

c MAF - Moisture and Ash Free
}

The first two pretreatments (COP-2-3 and COP-4-4) involved preheating the coal in an IFB dryer using $\mathrm{CO}_{2}$ and $\mathrm{CO}_{2}-\mathrm{steam}$ as fluidizing gases. The dried coal was immersed into a preheated drum of the mild gasification liquid. The resulting slurry was then processed through the PDU available at WRI. This processing scheme uses thermal pretreatment at atmospheric pressure in the presence of an inert atmosphere. Details of these experiments are reported elsewhere (Vaillancourt et al. 1991). The solid product generated from the RDU was used as the co-processing feed for the investigations conducted under hydrogen pressure in the batch autoclave. The third pretreated coal (COP-7-2) was generated by processing undried coal through the PDU before co-processing under hydrogen pressure in the batch autoclave.

The two catalyst, precursors, ferrocene and iron pentacarbonyl, and the carbon disulfide were supplied by Aldrich Chemical Company and used as received. 
Table 3. Proximate and Ultimate Analyses of Illinois No. 6 Coal Thermally Pretreated in the PDU

\begin{tabular}{|c|c|c|c|c|c|}
\hline \multicolumn{6}{|c|}{ Proximate Analysis } \\
\hline Sample & & Moisture & Ash & Volatile & Fixed Carbon \\
\hline \multirow[t]{3}{*}{$C O P-2-3$} & $\mathrm{AR}^{\mathrm{a}}$ & 0.7 & 5.9 & 60.8 & 32.6 \\
\hline & $\mathbf{M F}^{\mathbf{b}}$ & & 5.9 & 61.2 & 32.8 \\
\hline & $\mathrm{MAF}^{\mathrm{C}}$ & & & 65.1 & 34.9 \\
\hline \multirow{3}{*}{$\mathrm{COP}-4-4$} & AR & 0.3 & 4.5 & 63.2 & 32.0 \\
\hline & MF & & 4.5 & 63.4 & 32.1 \\
\hline & MAF & & & 66.4 & 33.6 \\
\hline \multirow[t]{3}{*}{ COP $-7-2$} & $A R$ & 1.2 & 10.1 & 45.0 & 43.7 \\
\hline & MF & & 10.1 & 45.5 & 44.2 \\
\hline & MAF & & & 50.7 & 49.3 \\
\hline
\end{tabular}

\section{Ultimate Analysis}

\begin{tabular}{llccccc}
\hline Sample & & Carbon & Hydrogen & Nitrogen & sulfur & Oxygen \\
\hline \multirow{2}{*}{ COP-2-3 } & AR & 73.9 & 5.9 & 1.1 & 2.4 & 10.8 \\
& MF & 74.4 & 5.9 & 1.1 & 2.4 & 10.3 \\
& MAF & 79.1 & 6.3 & 1.2 & 2.6 & 10.9 \\
\hline \multirow{2}{*}{ COP-4-4 } & AR & 76.3 & 6.1 & 1.3 & 2.3 & 9.5 \\
& MF & 76.5 & 6.1 & 1.3 & 2.3 & 9.3 \\
& MAF & 80.1 & 6.4 & 1.4 & 2.4 & 9.7 \\
\hline \multirow{2}{*}{ COP-7-2 } & AR & 69.9 & 6.0 & 1.1 & 3.8 & 9.4 \\
& MF & 70.7 & 5.9 & 1.1 & 3.8 & 8.3 \\
& MAF & 78.8 & 6.6 & 1.2 & 4.2 & 9.2 \\
\hline
\end{tabular}

\footnotetext{
a AR - As Received

b MF - Moisture Free

c MAF - Moisture and Ash Free
}

\section{Experimental Apparatus}

Tubing Bombs

The tubing bombs used for the co-processing studies were constructed from 7.5 inch long by 0.75 inch $0 . d$. stainless tubing, with an inside diameter of $0.625 \mathrm{inch}$. The ends of the tubes (bombs) were sealed with swagelok caps. A 1.0 inch length $(0.25$ inch $0 . d$.$) of stainless steel$ tubing was welded perpendicular to the length of each tube (bomb). The 0.25-inch diameter tubing was placed 2 inches from one end of the bomb. 
The 0.25-inch diameter tubing was attached to a 0.125 -inch diameter tubing ( 18 inches long) by means of a swagelok reducing union. The open end of the 0.125 inch tubing was fitted with a valve to allow introduction and venting of gases.

Normally $1.0 \mathrm{~g}$ of IFB dried coal and $3.0 \mathrm{~g}$ of the mild gasification liquid were charged to each tubing bomb. The catalyst precursor was added at a weight to represent 1.0 wt of the metal on the basis of the coal charge. Carbon disulfide was added as an excess to ensure sulfiding of the metal catalyst during co-processing. After loading, each tubing bomb was frozen at $-80^{\circ} \mathrm{C}\left(-112^{\circ} \mathrm{F}\right)$ and evacuated to remove air.

Pretreatment experiments were performed by pres;"izing the bombs with 20 psig of helium (pressure at room temperature) and placing them in the sand bath at the pretreatment temperature for the desired time period. After pretreatment, the bombs were frozen to prevent loss of the carbon disulfide and the helium vented. The tubing bombs were then pressurized to $800 \mathrm{psig}$ by addition of hydrogen (pressure at room temperature). The tubing bombs were heated in a sand bath set at $400^{\circ} \mathrm{C}$ $\left(752^{\circ} \mathrm{F}\right.$ ) and shaken at a rate of 100 cycles per minute for 60 minutes. At the end of each experiment, the tubing bombs were rapidly cooled to quench the reactions.

The tubing bombs were vented into a chamber of known volume, the pressure measured, and a sample of gas taken for analysis. The tubing bombs were disassembled, the components placed in extraction thimbles, and extracted with tetrahydrofuran (THF) for 48 hours. The THF was removed from the soluble fraction with a rotary evaporator until a constant weight of the extract was achieved. The residual solid material from the extraction was dried in a vacuum oven at $80^{\circ} \mathrm{C}\left(176^{\circ} \mathrm{F}\right)$ for 24 hours and the weight determined. The dried solid was ashed at $427^{\circ} \mathrm{C}\left(800^{\circ} \mathrm{F}\right)$ for 16 hours. The weight of residual organic material (unconverted coal) was determined by difference. The concentrations of hydrogen and other product gases were determined by gas chromatography. coal conversion was calculated as a weight percentage by dividing the mass of unconverted coal by the difference between the initial mass of coal used and the mass of ash recovered. The resulting fraction was multiplied by 100 to obtain the weight percentage of unconverted coal.

Hydrogen consumption was calculated based on the initial mass of coal on a dry mineral free (dmf) basis was charged to the reactor. The difference between the initial mass of hydrogen and the mass of hydrogen remaining at the end of the experiment is divided by the initial mass of coal (dmf) charged to the reactor. The result is multiplied by 100 to obtain the hydrogen consumption as a weight percentage. The initial mass of hydrogen charged to the reactor is calculated from the hydrogen pressure charged to the reactor and the volume of the tubing bombs using the ideal gas law. The mass of hydrogen remaining in the reactor at the end of an experiment is calculated from the results of the gas analysis, the final pressure, and the volume of the tubing bomb and expansion chamber using the ideal gas law. 


\section{Batch Autoclave}

The experiments to investigate co-processing of the IFB dried coal and coal pretreated in the 2 -inch PDU were performed in the WRI batch autoclave, a stirred reaction vessel designed and built by the TEM-PRES Division of LECO. The reaction vessel is constructed of carpenter 20 $\mathrm{Cb}-3$ steel and has a capacity of 1 liter. Heating of the vessel contents is accomplished by an electric heater located around the periphery of the vessel. Agitation within the vessel is accomplished through a belt-driven magnetic stirrer. The shaft is externally cooled by circulating water and is turned at approximately $600 \mathrm{rpm}$. The autoclave is surrounded by a vertical tube furnace capable of a maximum temperature of $700^{\circ} \mathrm{C}\left(1292^{\circ} \mathrm{F}\right)$. The furnace provides additional heat during the initial heating of the autoclave and prevents heat loss at operational temperature assuring better temperature contrcl of the reaction.

The batch autoclave was charged with the mild gasification liquid and coal at a weight ratio of $2: 1$. The catalyst and sufficient carbon disulfide to ensure an excess of sulfur to convert the catalyst to the sulfide form were added last. The autoclave was sealed and charged with hydrogen at $1500 \mathrm{psig}$. The autoclave was then brought to a reaction temperature of $400^{\circ} \mathrm{C}\left(752^{\circ} \mathrm{F}\right)$ as fast as possible and held there for 1 hour. The reactor was cooled by opening the tube furnace and blowing air through the cooling coils attached to the reactor.

After the reactor reached room temperature, the autoclave was vented into an expansion chamber of known volume, the pressure measured, and a gas sample taken for analysis. Tetrahydrofuran (THF) was then added to the autoclave and stirred to dissolve the co-processing products. The resulting slurry was then poured into a container for transfer to a soxhlet extractor. The contents from the reactor wash were extracted with THF for 48 hours using the same procedure used for extraction of the contents from the tubing bomb experiments. The coal conversion and hydrogen consumption values were calculated in the same manner as was used for the tubing bomb experiments.

\section{Analytical Procedures}

The oil traction was generated from the THF-soluble product by solubility in cyclohexane. A $1 \mathrm{~g}$ sample of the THF-soluble product was added to $40 \mathrm{ml}$ of cyclohexane and stirred for 16 hours. The solution was filtered, the solvent removed from the oil fraction by rotary evaporation, and its weight determined. The insoluble material was dried and its weight determined.

Elemental composition of the THF-soluble product and the cyclohexane soluble oil was determined using conventional methods. Carbon, hydrogen, and nitrogen were determined by combustion using a perkin Elmer $2400 \mathrm{cHN}$ analyzer. Sulfur concentration was determined with a Fisher sulfur analyzer, and oxygen determined by coulometric titration. 


\section{RESULTS AND DISCUSSION}

\section{Evaluation of Catalyst Dispersion}

\section{Catalyst screening studies}

A series of co-processing expe:iments were performed in the tubing bomb reactors to evaluate the actirity of the two oil-soluble catalyst precursors. A pretreatment step uncler a helium atmosphere was performed as part of each co-processing expe:-iment to ensure good mixing of the reactants, to swell the coal, and to allow the liquid-catalyst precursor solution to enter the coal structure. The pretreatment was not performed under hydrogen so the resulis of this study could be used to evaluate the effects of coal swelling without interference from effects of low temperature hydroliquefaction (Derbyshire et al. 1990). pretreatment at $90^{\circ} \mathrm{C}\left(194^{\circ} \mathrm{F}\right)$ for 30 minutes was selected as the base condition for this study because this condition provides sufficiently high temperature to decrease viscosity of the co-processing liquid and allow good mixing of the reactants without thermally altering the coal structure. Pretreatment at $275^{\circ} \mathrm{C}\left(527^{\circ} \mathrm{F}\right)$ for 30 minutes was performed tc swell the coal by both thermal and solvent interaction with the coal, and allow the liquid and dissolved catalyst access to the coal structure before co-processing. The results of this study are listed in Table 4.

The results provided in Table 4 include the experimental conditions, material balance closures, coal conversions, and hydrogen consumption data for each of the experiments. The coal conversion is calculated as the percentage of unconverted coal remaining after the experiment based on the mass of coal (less mineral matter) charged to the reactor. Hydrogen consumption is reported as the percentage of hydrogen consumed based on the mass of coal (dmf) charged to the reactor. Examination of the material balance closures shows they range from about 102 to 108 wt 8. These values are typical of our reaction system and are considered to be acceptable since material balances from other studies are frequently below 90 wt 8 (Ceylan and stock 1991). The reason for our closures being above 100 wt 8 results from the difficulty in removing all of the THF and the anti-oxidant present in the solvent from the small quantity of THF-soluble product. The THF remaining in the extract increases the reported value of the extract and causes the material balance closures to be greater than 100 wt 8 .

Coal conversions for each coal are significantly higher when iron pentacarbonyl is used as the catalyst precursor compared to ferrocene. This result indicates iron pentacarbonyl is either converted to the more active sulfided form than is ferrocene or it is better dispersed in the coal structure. In all of the experiments using iron pentacarbonyl as the catalyst precursor, higher conversion was observed for pretreatment at $275^{\circ} \mathrm{C}\left(527^{\circ} \mathrm{F}\right)$ as compared with pretreatment at $90^{\circ} \mathrm{C}\left(194^{\circ} \mathrm{F}\right)$.

Ferrocene does not form as active a catalyst as does iron pentacarbonyl. Examination of the results from the experiments using ferrocene as the catalyst precursor show coal conversion is lower than with iron pentacarbonyl. The differences in the activity of the two catalyst systems confirm work by other researchers that shows iron pentacarbonyl is the more active catalyst for co-processing coal (Kamiya et al. 1988; Watanabe et al. 1984). 


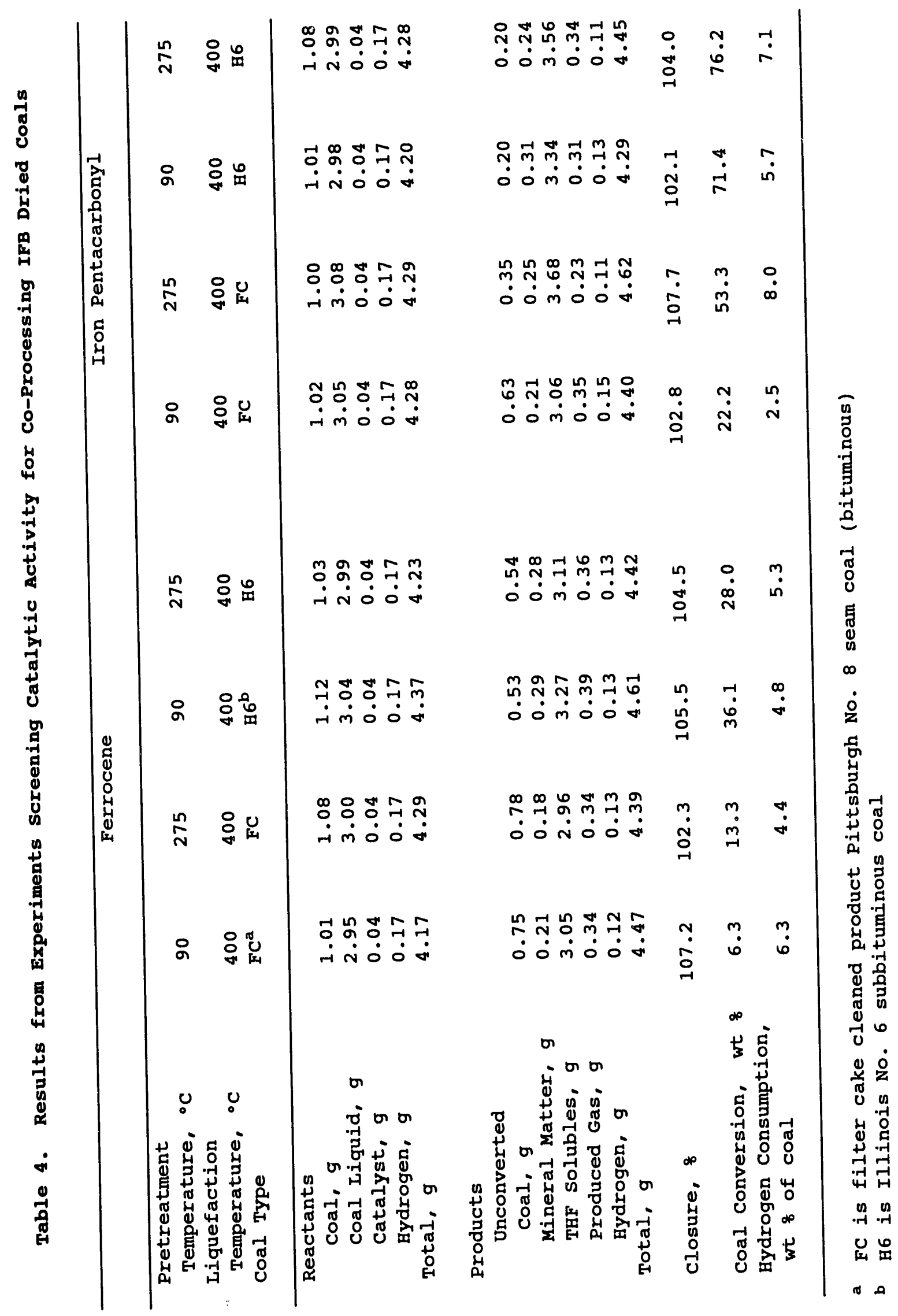




\section{Evaluation of Pretreatment and Co-Processing}

A series of experiments were performed in the tubing bomb reactors to evaluate pretreatment (under helium) followed by co-processing each coal with the mild gasification liquid (under hydrogen) using iron pentacarbonyl as the catalyst precursor. The experiments were designed to evaluate pretreatment of the coal to induce swelling and allow better dispersion of the catalyst precursor. Catalyst dispersion, as a result of coal swelling, was monitored by changes in coal conversion and hydrogen consumption as compared to the baseline data using pretreatment at $90^{\circ} \mathrm{C}\left(194^{\circ} \mathrm{F}\right)$ for 30 minutes without the catalyst. The results of the investigations with the Illinois No. 6 coal are listed in Table 5. The material balance closures for these experiments are in the range expected for the tubing bomb reactors (101-113 wt 8$)$.

Comparison of coal conversion (Table 5) for the two experiments performed without catalyst show the experiment conducted at $275^{\circ} \mathrm{C}$ $\left(527^{\circ} \mathrm{F}\right.$ ) had higher conversion than the experiment conducted at $90^{\circ} \mathrm{C}$ $\left(194^{\circ} \mathrm{F}\right)$. The increase in the coal conversion is caused from disruption of the weaker bonds (carboxylic acid functions and ethereal linkages) in the coal structure during the higher temperature pretreatment. This behavior is expected for subbituminous coals with high oxygen content (Derbyshire et al. 1990). These results are confirmed by comparison of the values of the hydrogen consumption. Although there is a small difference in the reported values, the difference is attributed to experimental error. Since there is no significant difference in the hydrogen consumption between the two experiments, the increase in coal conversion results from disruption of the weaker bonds during the higher temperature pretreatment rather than from increased conversion during co-processing under a hydrogen atmosphere.

Comparison of the coal conversions and hydrogen consumptions for the two experiments pretreating the reactants at $90^{\circ} \mathrm{C}\left(194^{\circ} \mathrm{F}\right)$ with the catalyst precursor shows there are no significant differences between the two experiments. The same observation is apparent in the two experiments pretreating the coal at $275^{\circ} \mathrm{C}\left(527^{\circ} \mathrm{F}\right)$. Comparison of the results for both pairs of experiments shows there is no significant differerce between the two pretreatment temperatures or the two pretreatment times ( 30 and 45 minutes). The differences between the experiments conducted with the catalyst as compared to those without are significant and the large differences in coal conversion and hydrogen consumption demonstrate catalyst activity is increasing coal conversion.

The absence of differences in coal conversion and hydrogen consumption as functions of pretreatment conditions can be explained by the behavior of the coal. Subbituminous coals (including Illinois No. 6) have been shown to undergo less swelling in solvents as compared to bituminous coals (Joseph 1991) and are more reactive under co-processing conditions (Derbyshire et al. 1990). The absence of improved yields at higher temperatures or longer residence times for the pretreatment of the Illinois No. 6 coal can be attributed to the coal reactivity being more important to coal conversion and hydrogen consumption than coal swelling. 


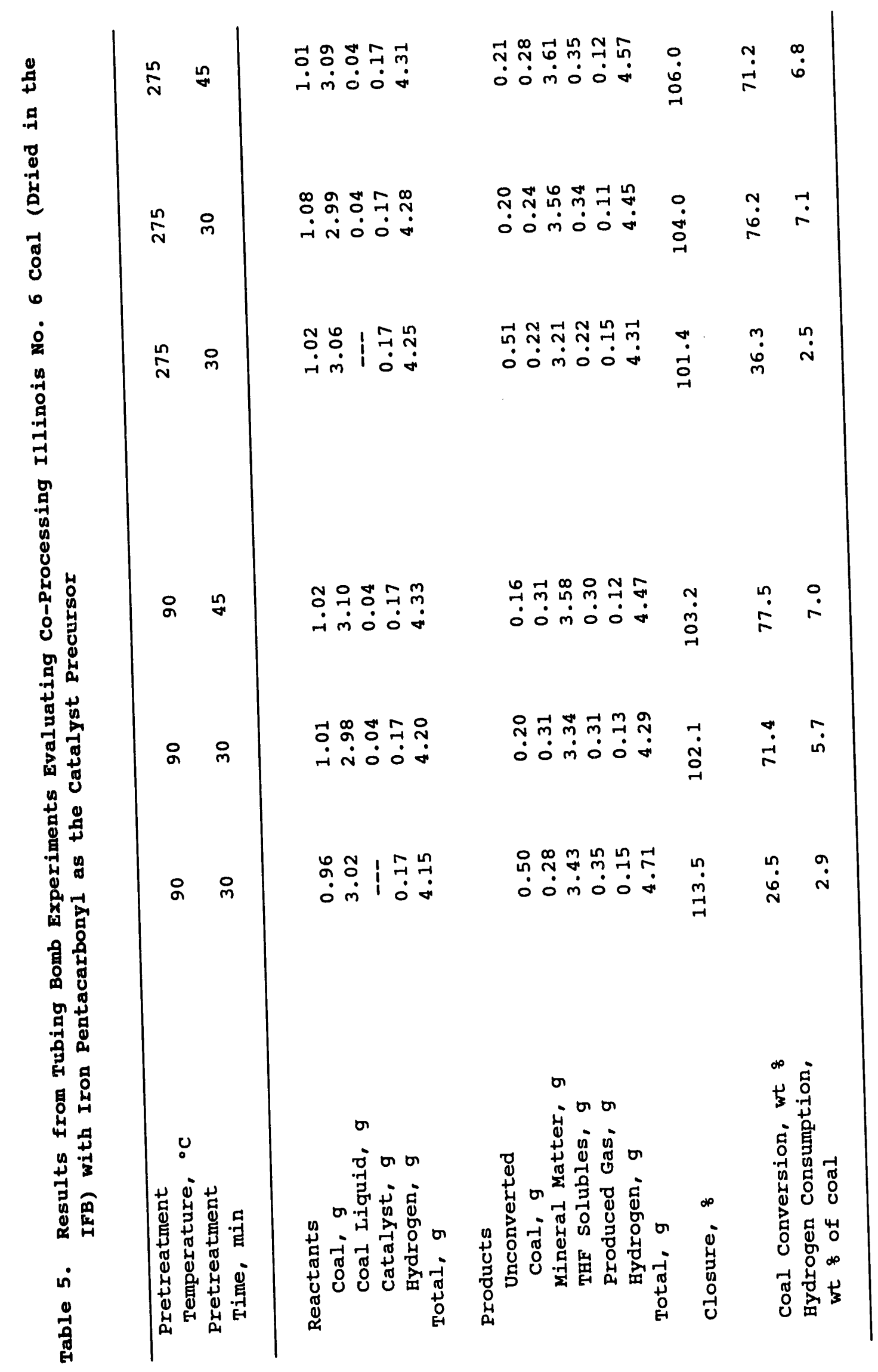


The results for the experiments investigating the filter cake product from Pittsburgh No. 8 coal are listed in Table 6 . The experiment conducted with pretreatment at $90^{\circ} \mathrm{C}\left(194^{\circ} \mathrm{F}\right)$ for 45 minutes has a material balance below 100 wt 8 . This lower material balance resulted from excessive time and temperature stress placed on the THFsoluble product during solvent removal in an attempt to remove all of the solvent. This stress resulted in the loss of light ends from this sample and the lower material balance closure.

Comparison of the coal conversion and hydrogen consumption for the two experiments conducted without the iron pentacarbonyl catalyst precursor shows the results are comparable, within experimental error. The absence of increased coal conversion with increased pretreatment temperature, which differs from the experiments using Illinois No. 6 coal, can be attributed to the lower reactivity of filter cake product which is derived from a bituminous coal (Derbyshire et al. 1990).

Increased pretreatment times for the experiments with catalyst show increased coal conversion and hydrogen consumption at both pretreatment temperatures. Increased coal conversion coupled with the increased hydrogen consumption indicates improved conversion from better catalyst activity. The explanation for this observation is swelling of the coal during the pretreatment step. Swelling of the coal allows the catalyst precursor, dissolved in the mild gasification liquid, to penetrate the coal structure and become more dispersed as a function of pretreatment time and temperature. The filter cake product is derived from a bituminous coal and shows a larger degree of swelling than the subbituminous Illinois No. 6 coal. This is consistent with published data that show bituminous coals normally have higher swelling indices than subbituminous coals (Joseph 1991).

Increasing the pretreatment time at $90^{\circ} \mathrm{C}\left(194^{\circ} \mathrm{F}\right)$ from 30 to 45 minutes increases the coal conversion from 22.2 to 50.0 wt 8 . This is a significant increase and shows the coal will undergo a significant degree of swelling caused by solvent interactions at the lower pretreatment temperature, if the residence time is sufficient. The coal conversion and hydrogen consumption observed for the experiment conducted with pretreatment at $90^{\circ} \mathrm{C}\left(194^{\circ} \mathrm{F}\right)$ and residence time of 45 minutes are comparable to the values observed at the shorter pretreatment residence time at $275^{\circ} \mathrm{C}\left(527^{\circ} \mathrm{F}\right)$. The most notable difference between the two experiments, if one considers the experimental errors discussed above, is in gas production. The higher mass of gas produced at $90^{\circ} \mathrm{C}\left(194^{\circ} \mathrm{F}\right)$ as compared to the higher temperature pretreatment indicates the catalyst may not have been as uniformly dispersed in the coal at the lower temperature which results in poorer utilization of hydrogen and production of gaseous products instead of the desired THF-soluble product. 


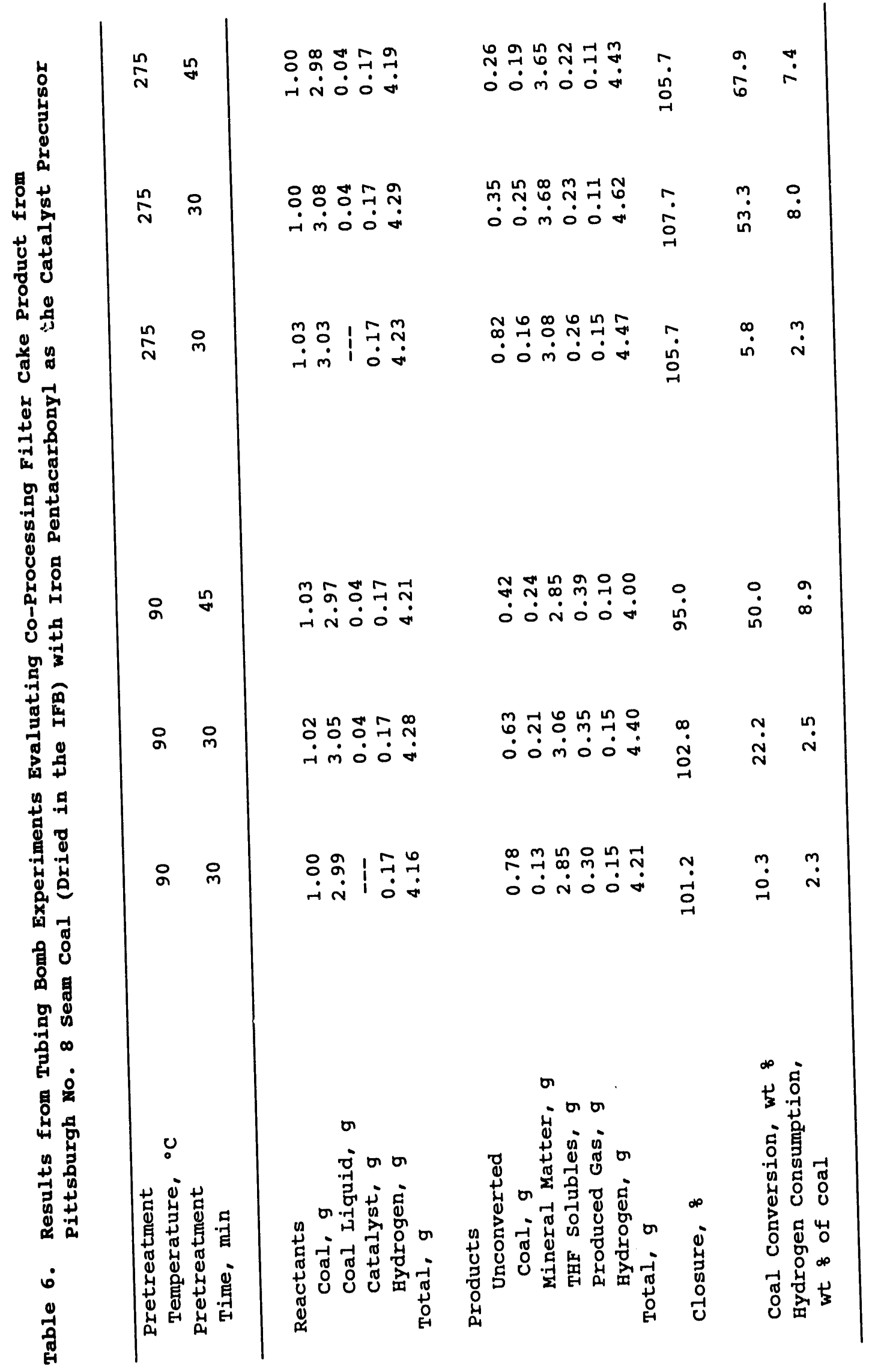


Coal conversion increases as a function of pretreatment time for the experiments conducted at a pretreatment temperature of $275^{\circ} \mathrm{C}\left(527^{\circ} \mathrm{F}\right)$, but the hydrogen consumption remains the same (within experimental error). Comparison of the relative product distributions (Table 7) shows the longer residence time experiment exhibited a lower percentage of unconverted coal (accounting for the higher coal conversion), the same percentage of produced gas, and a higher percentage of THF-soluble product. These results demonstrate that the higher coal conversion (Table 6) reported for the experiment using 45 minute pretreatment at $275^{\circ} \mathrm{C}\left(527^{\circ} \mathrm{F}\right)$ results from coal conversion to THF-soluble product. The higher conversion to THF-soluble product shows that the longer pretreatment time improves coal conversion by obtaining a better dispersion of the catalyst through the coal structure which enhances conversion to the desired THF-soluble product.

Table 7. Relative Product Distribution for the Experiments Conducted with the Filter cake product using pretreatment at $275^{\circ} \mathrm{C}\left(527^{\circ} \mathrm{F}\right)$

\begin{tabular}{lrr}
\hline & \multicolumn{2}{c}{ Pretreatment Time, min } \\
\cline { 2 - 3 } & 30 & 45 \\
\hline Unconverted Coal, wt 8 & 7.6 & 5.9 \\
Mineral matter, wt 8 & 5.4 & 4.3 \\
THF Solubles, wt \& & 79.7 & 82.4 \\
Produced Gas, wt 8 & 5.0 & 5.0 \\
Hydrogen, wt \& & 2.4 & 2.5 \\
Total, wt \& & 100.0 & 100.0 \\
\end{tabular}

The results from the co-processing studies performed in the tubing bomb reactors show coal conversion increases with increased pretreatment time. The pretreatment procedure was designed to promote coal swelling; therefore, these results coupled with other results from the literature, indicate swelling is more pronounced with the filter cake product from pittsburgh No. 8 coal than with the Illinois No. 6 coal. The increased swelling is caused by the higher swelling propensity of the bituminous filter cake coal, as compared with the subbituminous, Illinois No. 6 coal (Joseph 1991). Even with the higher degree of swelling, the conversion obtained from the Illinois No. 6 coal is higher than observed for the filter cake coal product. The higher conversion of the Illinois No. 6 coal is a result of the higher reactivity of a subbituminous coal as compared to a bituminous coal (Derbyshire et al. 1990). In terms of selecting a coal for processing with the mild gasification liquid in a commercial application, the Illinois No. 6 coal would have to be selected because of the significantly higher coal conversion. Additional investigations of co-processing the Illinois No. 6 coal with the mild gasification liquid were conducted in the batch-autoclave to obtain data relating to product quality. 
Batch-Autoclave Tests

\section{Experiments Investigating Dried Coal}

Two experiments were conducted in the batch-autoclave with Illinois No. 6 coal and the mild gasification liquid to generate sufficient THFsoluble product for analysis. One of the experiments was conducted in the absence of the iron pentacarbonyl catalyst precursor and the second with the added catalyst precursor. The cold hydrogen pressure used for these experiments was increased from 800 psig, as used for the tuling bomb, to $1500 \mathrm{psig}$, and the co-processing liquid to coal mass ratio was decreased from $3: 1$ to $2: 1$ to enhance product quality. A separate pretreatment step was not included in these experiments because the relatively slow heating rate of the autoclave requires 25 to 30 minutes to raise the temperature from 225 to $325^{\circ} \mathrm{C}$ (437 to 617 ${ }^{\circ} \mathrm{F}$ ). This provides sufficient time for thermal pretreatment. The results of these experiments are listed in Table 8. The material balance closures are 101.7 and 99.4 wt 8 and are considered well within the range of acceptability for these experiments.

Table 8. Results from stirred Batch Autoclave Experiments Co-Processing IFB Dried Illinois No. 6 Coal with Iron Pentacarbonyl as the Catalyst Precursor at $400^{\circ} \mathrm{C}\left(752^{\circ} \mathrm{F}\right)$

\begin{tabular}{lrr}
\hline $\begin{array}{l}\text { Iron Catalyst } \\
\text { Present }\end{array}$ & No & Yes \\
\hline & & \\
Reactants & 50.04 & 26.25 \\
Coal, g & 100.70 & 52.00 \\
Coal Liquid, g &.-- & 1.75 \\
Catalyst, g & 8.17 & 8.82 \\
Hydrogen, g & 158.91 & 88.82 \\
Total, g & & \\
Products & 2.42 & 0.57 \\
Unconverted Coal, g & 6.75 & 3.85 \\
Mineral Matter, g & 126.34 & 63.45 \\
THF Solubles, g & 8.12 & 7.15 \\
Produced Gas, g & 6.98 & 8.05 \\
Hydrogen, g & 10.91 & 5.23 \\
Water, ga & 161.52 & 88.30 \\
Total, g & 101.6 & 99.4 \\
Closure, \& & 94.4 & 97.5 \\
Coal Conversion, wt o & 2.7 & 3.4 \\
Hydrogen Consumption, & & \\
wt of coal & & \\
\hline
\end{tabular}

a Water determined by oxygen balance. 
The results (Table 8 ) show the coal conversion in both experiments is significantly higher than was observed in the tubing bomb experiments. This observation is attributed to the higher hydrogen pressure as compared to the tubing bomb experiments and to low temperature hydroliquefaction. The higher hydrogen pressure will increase coal conversion by making more hydrogen available to produce the THF-soluble product and produced gas. The length of time ( 35 to 40 minutes) required to heat the autoclave from 350 to $400^{\circ} \mathrm{C}\left(662\right.$ to $752^{\circ} \mathrm{F}$ ) is sufficiently long to allow the coal to undergo low temperature hydroliquefaction. Low temperature hydroliquefaction has been demonstrated to drastically improve coal conversion by utilizing slower reaction rates of coal dissolution to compensate for diffusion limitations of hydrogen availability (Derbyshire et al. 1986). The hydrogen consumption is lower for the batch-autoclave experiments as compared to the tubing bomb experiments and is attributed to the lower liquid to coal mass ratio which decreases the amount of hydrogen added to the mild gasification liquid.

\section{Experiments Investigating Thermally pretreated Coal}

The three thermally pretreated Illinois No. 6 coals (Vaillancourt et al. 1991), as described in the Introduction, were produced by processing the IFB dried coal in the PDU. This was followed by co-processing the solid product in the batch-autoclave with mild gasification liquid to evaluate the pretreatment approach using the PDU. Each sample was tested with and without iron pentacarbonyl catalyst precursor added. The cold hydrogen pressure used for these experiments was the same as the other batch autoclave experiments $(1500 \mathrm{psig}$ and the co-processing liquid to coal mass ratio was $2: 1$ ). The results of these experiments are listed in Table 9. The material balance closures range from 98.6 to 102.7 wt 8 and are considered within the range of acceptability for these experiments.

The presence of the iron pentacarbonyl catalyst precursor enhanced the conversion of the thermally pretreated coals. Without the catalyst present only 85 to 87 wt of of the coal was converted to THF-soluble product. The addition of the catalyst increased the conversion to approximately 96 wt 8 . Similarly, the hydrogen consumption also increases with the addition of the catalyst. It is interesting to note that no differences between the three thermal pretreatment regimes can be detected from the co-processing results. All of the tests run without catalyst are quite comparable. The same can be said for the coal-oil co-processing tests with the added catalyst precursor.

The thermal pretreatment of the coals adversely affected the coaloil co-processing under hydrogen pressure. Comparison of the results from the experiments conducted on the thermally pretreated coals (Table 9) with those on the dried coal (Table 8) show that there was less coal conversion. Even without the catalyst added, the sample that was only dried exhibited coal conversion comparable to the pretreated samples with the catalyst present. The hydrogen consumption for the thermally pretreated coals without the catalyst was considerably lower than the dried coal as well as all of the catalyst added tests. 


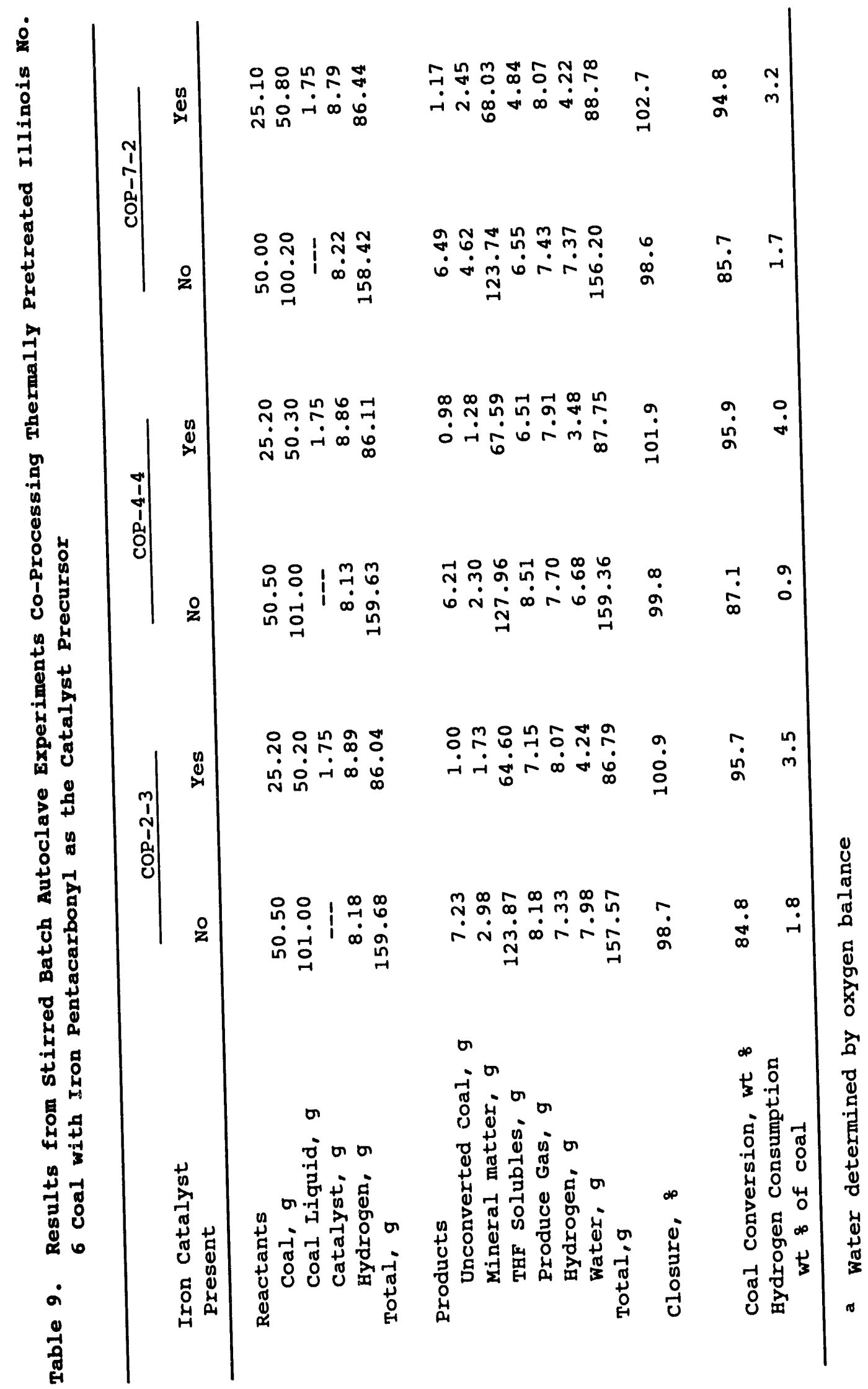




\section{Product Analysis}

The THF- and cyclohexane-soluble products generated from the batch autoclave experiments investigating the IFB dried Illinois No. 6 coal, and the initial mild gasification liquid were analyzed. The results of these analyses are listed in Table 10. Comparison of the elemental composition of the mild gasification liquid and the THF-soluble products from both experiments shows there is a significant increase in the percentage of carbon after co-processing, even in the absence of a catalyst. The hydrogen and nitrogen percentages are the same, within experimental error, for the four samples. The percentage of sulfur increases from 0.5 wt $\&$ to about 1.1 wt 8 from the addition of the coal dissolution products from co-processing a coal higher in sulfur as compared to the coal used to generate the mild gasification liquid. The oxygen percentage shows a marked decrease in both THF-soluble products as compared to the mild gasification liquid.

Table 10. Results from Analysis of THF-soluble Product and Cyclohexane Fractions from Batch Autoclave Experiments Investigating Illinois No. 6 Coal

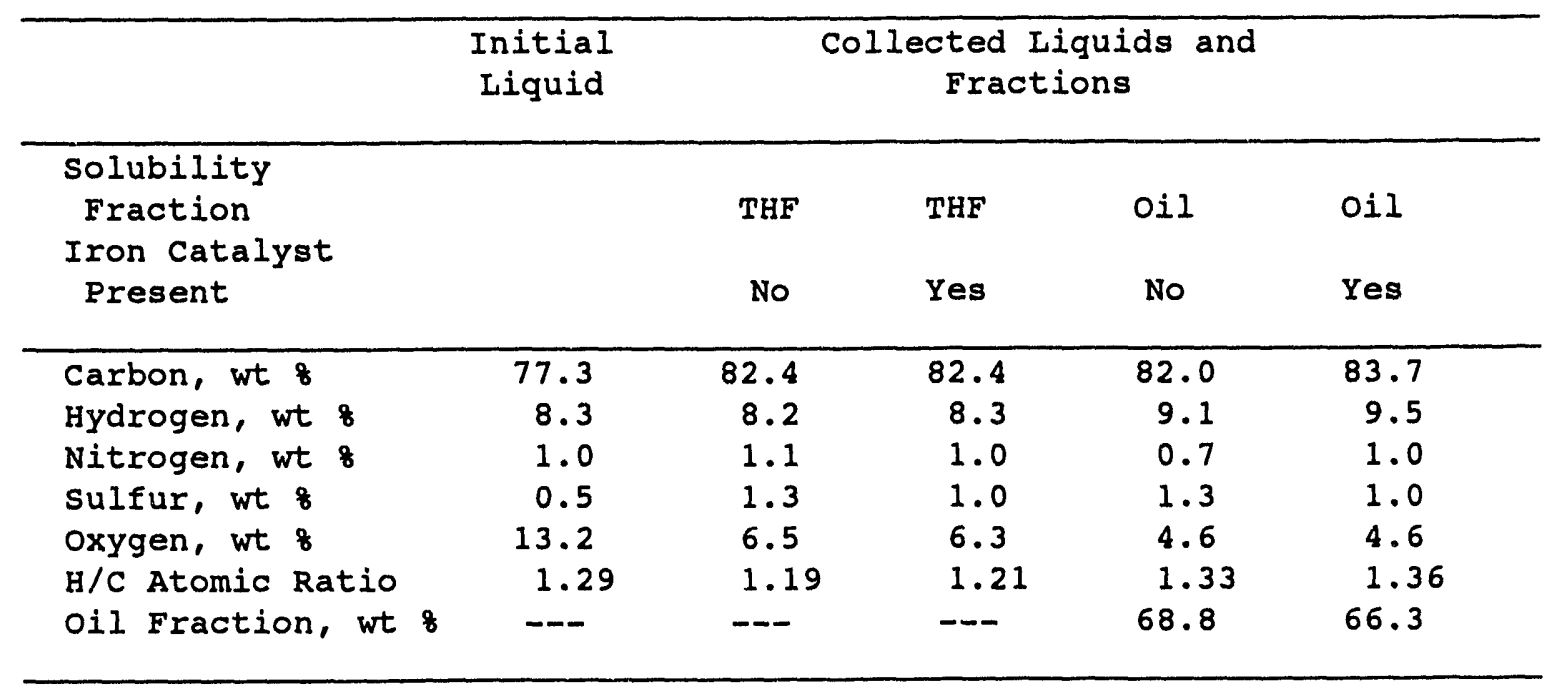

The increase in the percentage of carbon without a corresponding increase in the hydrogen concentration (decrease in the hydrogen to carbon atomic ratio) in the THF-soluble products as compared to the mild gasification liquid is indicative of coal dissolution. Dissolution of the highly aromatic structure of coal is expected to increase carbon percentage without greatly affecting the hydrogen percentage. The decrease in the oxygen percentage observed in the THF-soluble products shows the products from co-processing are upgraded as compared to the mild gasification liquid. These results demonstrate that a significant fraction of the hydrogen consumption is being used to greatly reduce the oxygen content of the mild gasification liquid and the coal dissolution products. 
The percentage of the oil fraction, as defined by solubility of the THF-soluble product in cyclohexane, is equivalent for the two experiments (Table 10). The percentage of carbon and hydrogen and the hydrogen to carbon (H/C) atomic ratio are slightly higher in the oil produced with the catalyst as compared to the oil produced without a catalyst, but the oxygen percentage is the same in both of the oil samples. The increased percentage of carbon and hydrogen and the higher H/C atomic ratio demonstrate that the addition of the catalyst produces a slightly upgraded oil as compared to co-processing without a catalyst.

\section{CONCLUSIONS}

The research discussed above was conducted to: (1) evaluate coal pretreatment to induce catalyst dispersion and (2) evaluate coprocessing coal that has been thermally pretreated in the presence of the mild gasification liquid. From the results of this investigation, the following conclusions can be made:

1. Iron pentacarbonyl is more effective as a catalyst precursor than is ferrocene for conversion of the Illinois No. 6 coal and the filter cake coal product derived from Pittsburgh No. 8 coal.

2. Induced coal swelling in the presence of the mild gasification liquid is a viable means of dispersing the catalyst. However, the two coals studied exhibit different degrees of improved yield from the pretreatment.

3. The filter cake product (bituminous) exhibited a higher degree of swelling and better catalyst dispersion, as defined by increased coal conversion, than did the Illinois No. 6 coal (subbituminous). The filter cake product showed a broader range of coal conversion percentages because of the induced swelling.

4. Even though the filter cake product showed a greater tendency to swell and disperse the catalyst, the Illinois No. 6 coal showed higher coal conversion in the tubing bomb experiments due to its higher reactivity.

5. Results from analysis of the product obtained from co-processing the Illinois No. 6 coal showed it was upgraded in terms of oxygen content and H/C atomic ratio when compared to the mild gasification liquid.

6. The thermal pretreatment of the coals adversely affected the coal-oil co-processing under hydrogen pressure. Thermally pretreated coals co-processed without catalyst present exhibited about 86 wt 8 conversion as compared to 96 wt 8 for coal that was only dried.

7. The addition of the iron pentacarbonyl catalyst precursor to the thermally pretreated coals did improve the conversion to near that of the dried coal. 


\section{ACKNOWLEDGEMENT}

The authors express appreciation to the United States Department of Energy for funding this work under Cooperative Agreement Number DE-FC21$86 \mathrm{MCl} 1076$.

\section{DISCLAIMER}

Mention of specific brand names or models is for information only and does not imply endorsement. 


\section{REFERENCES}

Ceylan, K. and L.M. Stock, 1991, Reaction Pathways during Coprocessing. Reaction of Illinois \#6 and Wyodak Coals with Lloydminster and Hondo Residua under Mild Conditions. Energy and Fuels, 5: 482-487.

Derbyshire, F., A. Davis, M. Epstein, and P. Stansberry, 1986 , Temperature-staged Catalytic Coal Liquefaction. Fuel, 65: 12331239.

Derbyshire, F., A. Davis, H. Schobert, and P. Stansberry, 1990, LowTemperature catalytic coal Hydrogenation: pretreatment for Liquefaction. ACS Div. Fuel Chem., 199th National Meeting, Boston, MA, April 22-27, p. 51-57.

Dukhedin-Lalla, L., P.M. Rahimi, and J.M. Shaw, 1990, Phase splitting and synergism in Coal oil Coprocessing and Coal Liquefaction. ACs Div. Fuel Chem., 35(4): 1040-1047.

Joseph, J.T., 1991, Liquefaction Behavior of Solvent-Swollen Coals. Fuel, 70: 139-144.

Kamiya, Y., T. Nobusawa and, S. Futamura, 1988, Catalytic Effects of Iron Compounds and the Role of sulfur in Coal Liquefaction and Hydrogenolysis of SRC. Fuel Processing Technology, 18: 1-10.

McMillen, D.F., R. Malhotra, and D.S Tse, 1991, Interactive Effects Between Solvent Components: Possible Chemical origin of synergy in Liquefaction and Coprocessing. Energy and Fuels, 5: 179-187.

Merriam, N.W., C.Y. Cha, T.W. Kang, and M.B. Vaillancourt, 1990, Development of an Advanced, Continuous Mild-Gasification Process for the production of Coproducts, Topical Report for Task 4, Mild Gasification Tests--system Integration studies. Laramie, WY, Western Research Institute Report to DOE, WRI-91-R023.

Speight, J.G and S.E. Moschopedis, 1986, The Co-Processing of Coal with Heavy Feedstocks. Fuel Processing Technology, 13: 215-221.

Vaillancourt, M., I.J. Fahy, and T.F. Turner, 1991, Initial study of Coal Pretreatment and Co-Processing. Laramie, WY, Western Research Institute Report to DOE, WRI-92-R002.

Warzinski, Robert, 1990, Catalyst Dispersion and Reagent Penetration. Proceedings Direct Iiquefaction Contractor's Review Meeting, Pittsburgh, PA, p. 320-336.

Watanabe, Y., O. Yamada, K. Fujita, Y. Takegami, and T. Suzuki, 1984, Coal Liquefaction Using Iron Complexes as Catalysts. Fuel, 63: $752-755$. 

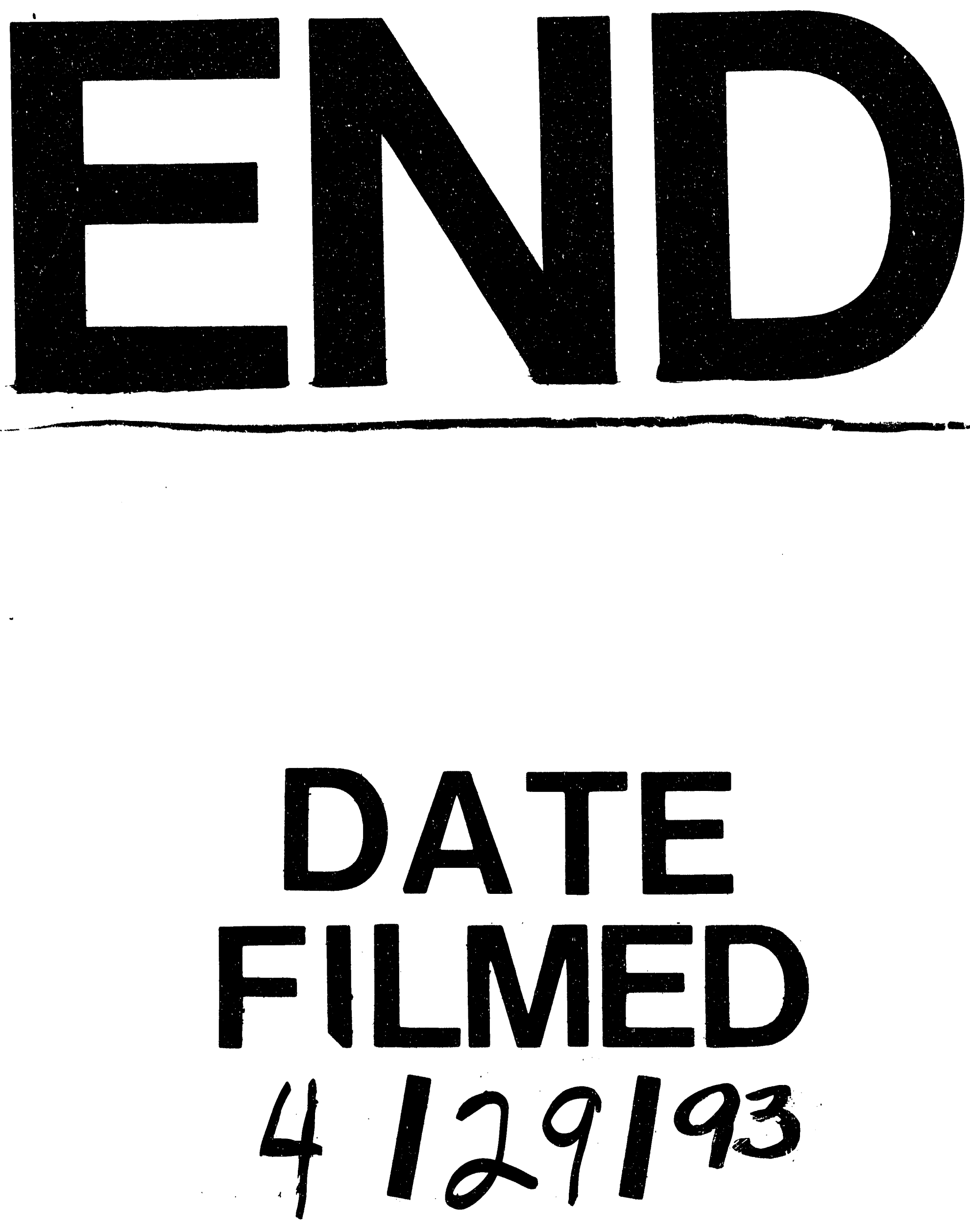
